\title{
Website owners and Part III of the Disability Discrimination Act 1995
}

by Sally Hayward

Many websites are not complying with the Disability Discrimination Act, and their designers and owners need to take remedial action in order to help disabled users and lift the threat of litigation.

\section{CURRENT LEVELS OF COMPLIANCE WITH THE DDA}

$\mathrm{T}$ o date, there have been no reported cases under Part III of the Disability Discrimination Act 1995 relating to the provision of web-based services. As the legislation has been in effect since October 1, 1999, that may lead the unwary to the conclusion that levels of compliance are good, and that there is no accessibility problem in the UK. Far from it. In April 2004, the Disability Rights Commission 2004 (DRC) reported the results of their investigation, "The Web: Access and Inclusion for Disabled People.”

The DRC commissioned the Centre for Human Computer Interaction Design at London's City University to survey 1,000 websites. Ten per cent of the sites were subjected to a detailed evaluation by a group of 50 users with a variety of impairments. In addition, sites were tested against the Web Content Accessibility Guidelines (W3C these can be found at www.w3.org). The guidelines provide comprehensive guidance on accessibility, and set three levels of conformance:

Level 'A': All priority 1 checkpoints met. Websites must satisfy this checkpoint.

Level 'AA': All priority 2 checkpoints met. Websites should satisfy this checkpoint.

Level 'AAA': All priority 3 checkpoints met. Website may satisfy this checkpoint.

The results were stark. Of websites tested, 81 per cent failed to satisfy the most basic Level A requirements, and 19 per cent met Level A only. As might be expected, government and the information sector fared better than others, but even then only 32 per cent of home pages achieved the lowest Level A compliance.

\section{Website designers' need for clearer guidance}

City University also invited the views of over 700 organisations that might commission websites, and 400 website developers. The report found that: "website designers have an inadequate understanding of the needs of disabled users and of how to create accessible websites, and would welcome clearer guidance.”

\section{Enforcement implications}

What are the legal implications of this general failure to comply with the DDA for website providers, owners, and designers, like advertising agencies? The DRC is clearly losing patience. As their report points out, it is not the first to have highlighted the problem. Similarly bleak reports were published by the RNIB in August 2000, the University of Bath in September 2002, and the Interactive Bureau in November 2002 (75\% of key government sites found to be in need of immediate attention). In the forward to the DRC investigation, Chairman Bert Massie states:

\footnotetext{
"Organisations that offer goods and services on the Web already have a legal duty to make their sites accessible. It is clear from the investigation that these are not being fulfilled. The Commission's policy is to seek improvement in the first instance through advice and conciliation... However, where the response is inadequate, we shall be vigorous in the use of our enforcement powers.”
}

Non-compliant providers are not only at risk of action from the DRC. Under section 25, legal action might also be brought either by a disabled user, or by a pressure group on their behalf. Providers therefore need to get to grips with the law, and to improve accessibility in order to avoid the dubious distinction of being the subject of the first UK case on web accessibility. 


\section{THE LAW}

Part III of the Disability Discrimination Act 1995 (the Act) has been in force since 1 October 1999. Section 19 makes it unlawful for a provider of services to discriminate against a disabled person. Discrimination includes making it impossible or unreasonably difficult for a disabled person to make use of a service, or to provide a lesser standard of service (s19 (1) (b) \& (c)).

Under section 21, providers of services are under a duty to make adjustments where a practice, policy or procedure makes it impossible or unreasonably difficult for disabled persons to make use of a service provided. Providers are required to take "such steps as... reasonable, in all the circumstances of the case" to change their practice, policy or procedure to negate or ease the difficulties created. The duty under section 21 is commonly known as the duty to make "reasonable adjustments."

\section{Application to commercial and non-commercial sectors}

Providers are not limited to those providing a service for profit. Under section 19(2)(c) it is irrelevant whether a service is provided with or without payment. It follows that most of the public sector, charities, voluntary organisations, hospitals, clinics, religious organisations, and even the courts are affected by the DDA. Unlike Part II of the Act, which exempts small businesses, there are limited exemptions under Part III. These are contained in section 19(5) and include educational establishments and transport services. However, the exemption is limited to the provision of education and transport. Services for parents such as school websites providing information, or online booking services for travellers would be included in Part III, together with privately run establishments providing higher education.

\section{How is disability defined?}

Disability is defined as a physical or mental impairment which has a substantial and long-term adverse affect on ability to carry out normal day to day activities. Impairments cover a wide range of physical or mental impairments, including sensory impairments and learning disabilities, such as dyslexia. Further information on the meaning of disability can be found at the Appendix to the DRC Code of Practice.

\section{What is a reasonable adjustment?}

The Code of Practice, which can be found at www.drc-gb.org, is a substantial document, with statutory authority under the Act. It provides comprehensive guidance and examples for service providers. It is a vital reference guide, comprehensively and clearly written.

However, the Code does not define what constitutes a reasonable adjustment, and, as yet, there is no UK case law to assist. The reported cases on Part III are listed on the
DRC website (see above). They mostly concern refusal of admission. However, guidance is provided by Australian and US authorities, which are discussed below.

\section{Australian and US authorities}

Bruce Lindsay Maguire v Sydney Organising Committee for the Olympic Games, HREOC No: H99/115, (Australian) Discrimination Act 1992, August 24, 2000

Mr Maguire, who is blind, made three complaints to the Human Rights and Equal Opportunity Commission. Two related to the non provision of information in Braille, the third concerned the Committee's failure to provide an accessible website. He was successful in proving that the website was in breach of the Australian DDA. This is similar to the UK Act, in that it is unlawful for providers of goods or services to discriminate against another person on the grounds of their disability, by refusing to provide goods or services, or in the terms \& conditions on which the goods or services are provided. The Commission found that the website failed to comply with the W3C guidelines, and that Mr Maguire had been treated less favourably because he was blind. There was no alternative text available for images and image map links, and the sports' index and results table were inaccessible. The Commission found that the detriment to $\mathrm{Mr}$ Maguire was "very significant" and took into account the "considerable financial funding including Government funding” available to the SOCOG, set against the relatively modest cost of making the necessary changes.

In the separate compensation hearing, at which $\mathrm{Mr}$ Maguire was awarded $\$ 20,000$ dollars, Hon William Carter QC of the Commission said:

"The suggestion that he enlist the help of a sighted person to assist him was wholly inconsistent with his own expectations and what he himself had been able to achieve, unaided, both at university level and in business, in spite of his disability. To dismiss him and to continue to be dismissive of him was not only hurtful, he was made to feel, I am satisfied, various emotions including those of anger and rejection by $a$ significant statutory agent within the community of which he was a part."

Attorney General of the State of New York Internet Bureau v Ramada.Com and Priceline.Com, Assurances of Discontinuance dated 12 August 12, 2004, and April 8, 2004

Ramada.Com operated a hotel booking website in New York, and Priceline.Com a website offering travel services and products. Eliot Spitzer, New York Attorney General, conducted an investigation into the accessibility of both companies' websites to the blind and visually impaired. Again, the American legislation, The Americans with Disabilities Act 1990, is similar to the UK's, in that it is unlawful for "public accommodation" to deny disabled 
individuals, on the basis of their disability, the opportunity to participate in or benefit from goods or services.

The Attorney General found that both companies failed to ensure their websites were accessible to the assistive technology used by the blind and visually impaired. To avoid litigation, the companies entered into a detailed written assurance, and paid $\$ 40,000$ plus costs, and $\$ 37,500$ plus costs respectively. As in the Maguire case, the W3C guidelines were used as a benchmark. The amendments required were set out in detail in each case, and included providing a text equivalent for images, an auditory description of important visual information, a prominent change font size button, and the provision of W3C training for programmers, together with guidelines for the implementation of change to comply with W3C.

\section{HOW TO AVOID LITIGATION AND BAD PUBLICITY}

\section{Involve disabled people}

Given the current non compliance with the DDA, it is only a matter of time before there is similar litigation in the UK to the cases cited above. Any website owner who offers a service - and this can extend to internal company intranets that offer employees information about job opportunities etc - should review the accessibility of their site. The W3C guidelines provide a useful starting point, but, as the Chairman of the DRC, Bert Massey points out in the foreword to the DRC investigation:

"It is ...clear that compliance with the technical guidelines and the use of automated tests are only the first steps towards accessibility: there can be no substitute for involving disabled people themselves in design and testing."

\section{Understand and follow the W3C guidelines, DRC Code and Investigation Recommendations}

All service providers would be wise to make themselves familiar with the W3C guidelines (www.w3.org), the DRC Code of Practice, and the DRC recommendations contained in their investigation (both at www.drc-gb.org).It is helpful to consider the DRC investigation's findings. As the foreword points out:

"Disabled people must frequently overcome additional obstacles before they can enjoy the full range of information, services, entertainment and social interaction offered by the Web: blind people need sites to provide, for example, text as an alternative to images for translation into audible or legible words by specially designed screenreading devices; partially sighted people may be especially reliant on large-format text and effective colour contrast; people who are dyslexic or have cognitive impairments may benefit in particular from the use of simpler English or alternative text formats, such as Easy Read, and from the clear and logical layout of an uncluttered website; people whose first language is British Sign Language may also find Plain English indispensable; and people with manual dexterity impairments may need to navigate with a keyboard rather than with a mouse."

A brief summary of the DRC recommendations are set out at the end of this article. These are split to distinguish between those which affect website owners and designers, and those that impact on Government, organisations for disabled people and educational establishments.

\section{Tackle key problems experienced by disabled users}

The most common key problems experienced by disabled users are set out below. Users were divided into six impairment groups: users who were blind, partially sighted, physically impaired, hearing impaired, or dyslexic. Interestingly, many problems were common to most of the different categories of disabled user. These were:

- Graphics and text size too small

- Inappropriate use of colours and poor contrast between content and background

- Incompatibility between accessibility software and web pages

- Unclear and confusing layout of pages

- Confusing and disorienting navigation mechanisms

Blind readers found alt tags on images either nonexistent or unhelpful - one of the accessibility issues on both the Maguire and Ramada.Com and Priceline.Com cases. Website owners would be well advised to address these problems as a priority.

\section{Awareness of the benefits of accessibility}

It remains to be seen whether, as recommended, government will champion accessibility, and put its own house in order; whether organisations for disabled people will be more proactive in offering advice to those who need it, and whether website owners will wake up to the fact that they are in breach of the law, and need to take urgent remedial action.

It is, after all, good business sense to extend the provision of goods and services to all. As New York Attorney General Spitzer pointed out, there are 450,000 blind or partially sighted people in New York. There must be thousands, if not millions of untapped or frustrated website customers and users with disabilities in the UK. As Bert Massie points out: "Making services accessible for disabled people is good for business."

Sally Hayward

Barrister, Gray's Inn; Compliance Director, Hidden Differences Group 
DRC RECOMMENDATIONS FOR WEBSITE

COMMISSIONERS, DESIGNERS AND

DEVELOPERS (CITED HERE IN BRIEF):

Recommendation 1:

Website commissioners should formulate written policies for meeting the needs of disabled people.

Recommendation 2:

Organisations which provide and oversee education and training for developers, including the vendors of webauthorising tools, should promote an understanding that good development practice entails attending, and responding, to the needs of disabled people.

\section{Recommendation 3:}

Website developers should accept that good practice entails attending and responding to the needs of disabled people.

\section{Recommendation 5:}

Website designers should involve disabled users from an early stage in the design process

\section{Recommendation 6:}

Website designers should not rely exclusively on automated accessibility testing.

\section{Recommendation 7:}

Developers of automated accessibility checking tools should enhance their functionality to make them more useful to website commissioners and website designers.

\section{Recommendation 10:}

Developers of operating systems and browsers should take steps to ensure that accessibility options are easier to discover, understand and select.

\section{Recommendation 11:}

The designers and providers of assistive technology should enable and encourage users to keep their products up to date.

\section{DRC RECOMMENDATIONS FOR GOVERNMENT, DISABILITY ORGANISATIONS, EDUCATIONAL ESTABLISHMENTS AND THE WEB ACCESSIBILITY INITIATIVE (CITED HERE IN BRIEF):}

\section{Recommendation 8:}

The Government should facilitate the development of best practice guidance for accessible website development and ongoing maintenance and thereafter promote a formal accreditation process.

\section{Recommendation 9:}

Organisations of and for disabled people should facilitate the enhancement of the skills required by disabled people to make full use of the Web, since they are uniquely placed to offer impairment-specific advice on these matters to those who need it.

\section{Recommendation 12:}

In line with its commitment to 'bridge the digital divide,' the Government should provide the funding required to enable access to appropriate technology for all those who need it, and to promote its better use.

\section{Recommendation 13:}

Existing health, social and rehabilitation services with responsibility for assessing their clients' needs for physical aids attend, and respond, to the Web accessibility needs of disabled people.

\section{Recommendation 14:}

Those professional bodies, colleges and universities involved in training key frontline personnel, such as information and computer technology trainers and librarians, should provide or review awareness and equality training in relation to computer and Web accessibility issues for disabled people.

\section{Recommendation 15:}

The Web Accessibility Initiative should give serious consideration to the proposals by City University for extending the scope of the guidelines to address limitations identified in the course of this investigation. 